\title{
New Materials Boost 39th SISC
}

www.ieeesisc.org

The 39th IEEE Semiconductor Interface Specialists Conference (SISC) was held on December 11-13, 2008, at the Catamaran Hotel in San Diego, Calif. The SISC is a workshop-style conference providing a forum for device engineers, materials scientists, and solid state physicists, and encouraging interplay between technological and scientific issues. In recent years the emphasis of the conference has shifted toward transistor and memory devices incorporating new materials, such as novel high- $k$ gate dielectrics, metal gate electrodes, and high carrier mobility substrates.

The program this year included 60 presentations from all areas of metal-oxidesemiconductor (MOS) science and technology. For the first time, a tutorial on electrical characterization of interface defects was offered free to all attendees. The core of the meeting was formed by invited talks from both industry (e.g., Intel, IBM, and Numonyx) and academia (e.g., the Pennsylvania State University, University of Texas, Stanford University, and the University of Tokyo). Materials issues addressed at SISC included incorporation of group-III elements into Hf-based dielectrics; work function modulation; and the impact of metal electrodes, such as TiN and $\mathrm{Ru}$, or novel dielectrics, such as $\mathrm{TiO}_{2}, \mathrm{SrTiO}_{3}$, or

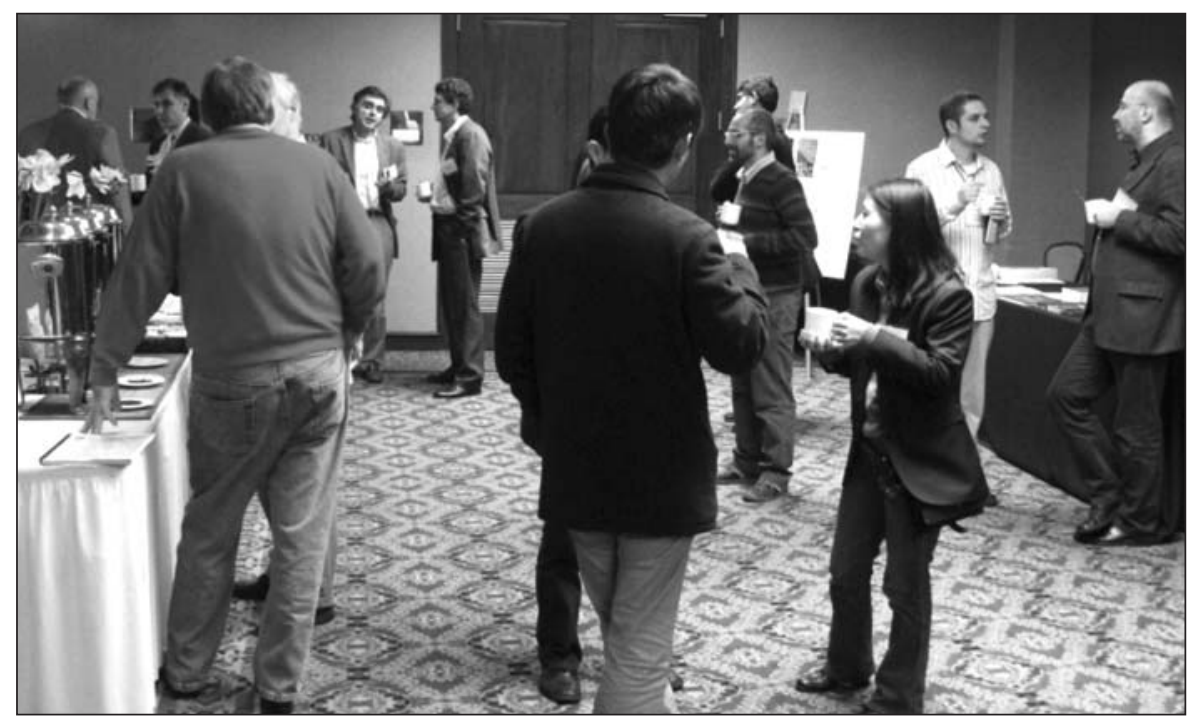

Attendees at the 39th IEEE Semiconductor Interface Specialists Conference enjoy lively discussion during a coffee break.

$\mathrm{YMnO}_{3}$. One full day was devoted to the interaction between dielectrics and highmobility substrates, such as Ge, GaN, GaAs, InGaAs, and AlInSb.

SISC was endorsed by the Materials Research Society. For more information about the conference and its program, see Web site www.ieeesisc.org. The 40th SISC will be held in Arlington, Va., on December 3-5, 2009.

BEN KACZER, IMEC SISC 2008 General Chair

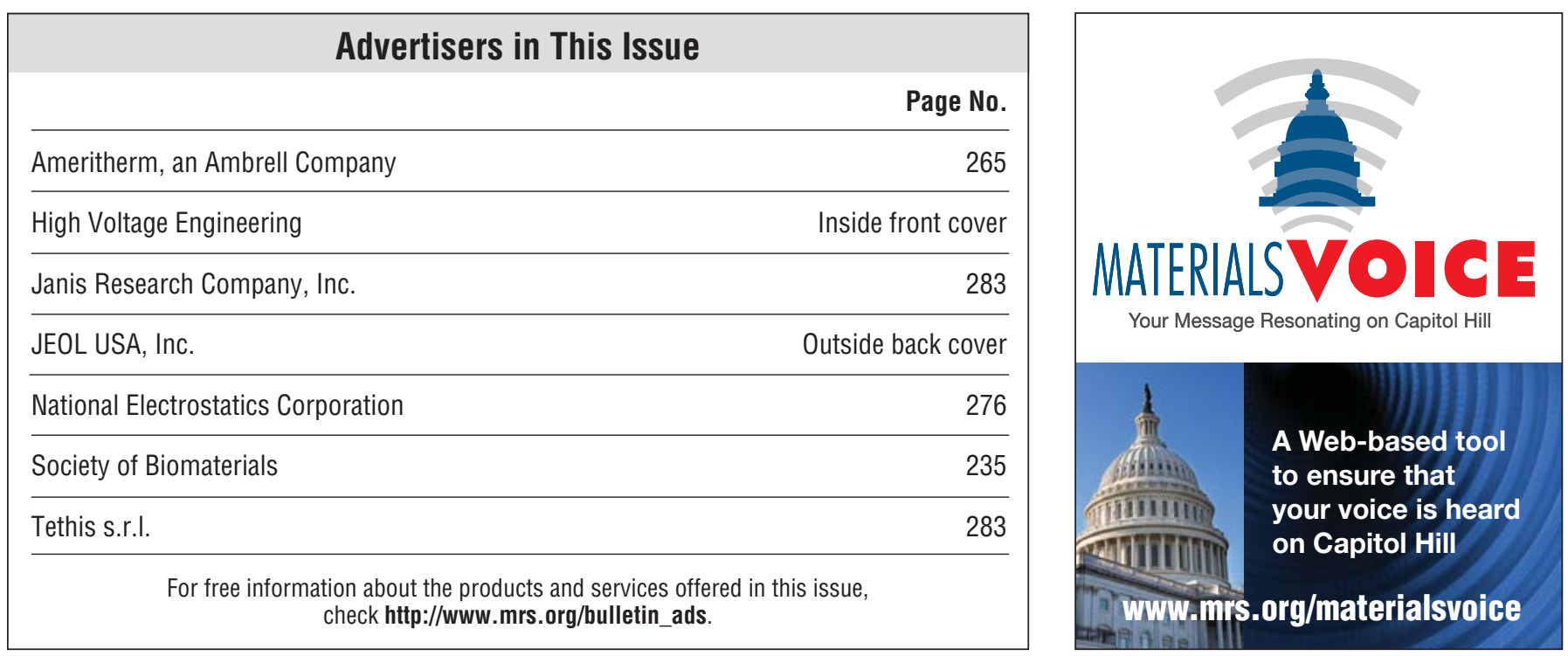

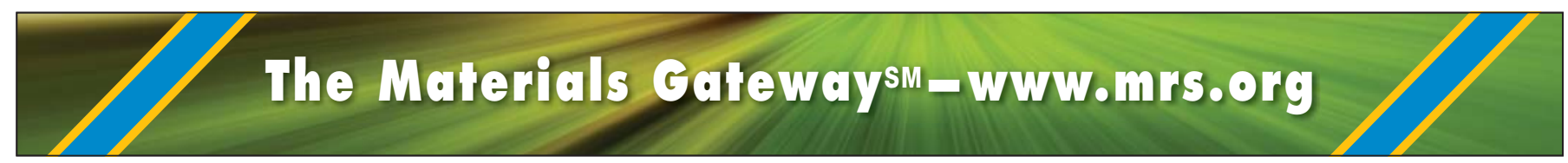

